\title{
An Empirical Study of Revenue Generation and Competitive Balance Relationship in European Football
}

\author{
Selçuk ÖZAYDIN*, Murat DONDURAN**
}

Received: March 20, 2019. Revised: August 2, $2019 . \quad$ Accepted: August 7, 2019.

\begin{abstract}
Distribution of income has been an important area of research in both economics and sports economics literature. However, the sports economics literature regarding European football lacks empirical studies associated with the relationship between revenue generation and competitive balance. This study analyzes the revenue sharing structure in Europe's top 5 football leagues along with its effects on competitive balance. Trends in the distribution of revenue are illustrated with the help of Lorenz curves and the coefficient of variations of revenue shares. There is significant evidence that there have been severe distortions in the distribution of revenue in European football, and it has been influential in the competition. The revenue shares of the top 5 leagues' have changed substantially over the last two decades which led to the utter dominance of European football by few clubs. The increasing inequality, in revenue generation and sharing, has affected the competitive balance adversely. The rising financial domination of the giants in European football is widening the gap between them and the lower profile teams hence decreasing the uncertainty of games, which might have adverse effects on the demand for football.
\end{abstract}

Keywords: Distribution of Income, Lorenz Curve, Revenue Sharing, Competition in European Football

JEL Code Classification: D3, Z2

UDC: $336: 64$

DOI: https://doi.org/10.17015/ejbe.2019.024.02

\footnotetext{
* Economics Department, MEF University, Istanbul, Turkey, E-mail: ozaydins@mef.edu.tr

** Professor, Economics Department, Yıldız Technical University, Istanbul, Turkey. E-mail: donduran@yildiz.edu.tr

Copyright @ , 2019 Ala-Too International University.
} 


\section{Introduction}

Income distribution has been crucially important for both academics and policymakers. Evaluating the trends in income distribution through time is as important as identifying the current distribution. In the case of sports economics literature, revenue distribution and sharing have been subject to numerous studies, due to its influence on competitive balance (Késenne, 2000; Zimbalist, 2002; Dietl et al., 2011), especially for the Northern American professional leagues where revenue sharing is controlled with regulations. In the case of European leagues, teams that can generate higher revenues can afford better players, staff, and facilities hence achieve higher success. In any branch of sport, a team that generates a higher revenue than the others will eventually dominate them all. This domination will lead to a decrease in the uncertainty of the games; therefore, it might decrease the demand for football (Forrest \& Simmons, 2002; Garcia \& Rodriguez, 2002), which constitutes the motivation for investigating the distribution and generation of revenue in European football.

The top 5 leagues of European football, England, France, Germany, Italy, and Spain, both in terms of revenue generation and attendance averages, have been the major focus of sports economics literature over the past decades. The top 5 leagues generated about 13.5 billion Euro revenue in the 2015/2016 season which is almost $54.5 \%$ of the total revenue generated by European football (Deloitte, 2017). There are 55 registered leagues in UEFA (UEFA, 2017), and the top 5 leagues generated more than half of the total revenue.

The revenue distribution is not only an issue between the top 5 leagues and the others but also an issue among the top 5 leagues. Revenue sharing has become more unequal over the years, especially English and German teams have increased their revenue significantly over the past two decades, whereas French and Italian teams have experienced dramatic decreases in relative terms. Deloitte releases an annual report about European football, called the Money League Report, and announces the top revenue-generating clubs. In the 2015/2016 season's report, there are 8 English, 4 Italian, 3 Spanish, 3 German, and 1 French club in the top 20, whereas in 1996/1997 season's report top 20 had 6 Italian, 5 English, 3 Spanish, 2 German and 1 French club. (Deloitte, 2017; Deloitte, 1998). Almost half of the most revenuegenerating clubs are the English clubs thanks to the broadcasting and sponsorship revenues. The weakest link in the top 5 leagues in terms of revenue generation is the French league. There is only one French team, Paris Saint-Germain, in the top 20, and there is one other, Olympique Lyonnais, in the top 30, which indicates the financial weakness of French clubs when compared to the other top 5 league teams. The latest Money League Report illustrates Italian clubs' worst ever Money League performance with only three clubs in the top 20 (Deloitte, 2018). Just like French teams, Italian teams are losing their financial power, which is likely to influence Italian teams' sportive performance. 
The numbers point out the unequal distribution of revenue in European football, which reflects on the European trophies won by clubs hence the uneven competition. In the last 20 years, the only team that is not from the top 5 leagues, has managed to win the Champions' League, which was Porto FC in 2004. In the 12 years before the last 20 years, teams from 9 different countries have managed to win the Champions' League (WorldFootball, 2017). The dramatic change in league and club finances in the last two decades has changed the competition structure of the inter-European competitions. The inequality in terms of revenue generation has reflected on success. Champions' League is no longer a league of champions' but a league where the same few teams compete to win the trophy every season.

Inequality in the revenue generation is an issue not only between the top 5 leagues and the rest of the European leagues but also among the top 5 leagues. From $1996 / 1997$ to $2015 / 2016$ season, the English Premier League has managed to increase its share in the total revenue generated by the top 5 leagues from $27,4 \%$ to $36,2 \%$. As expected, the total transfer spending increased accordingly during the same period. In the 1996/1997 season, Premier League clubs spent about 185 million euros, in 2005/2006 497 million euros, in 2010/2011 689 million euros and 2015/2016 1450 million euros (Transfermarkt, 2016). In the last decade, English Premier League clubs increased their total transfer spending by almost one billion euros, whereas Spanish, German, and French teams were able to increase their total spending about 200-250 million euros each (Transfermarkt, 2016). The growing financial power of English clubs has created inequality in terms of transfers. The accumulation of talent in the Premier League results in uneven competition especially between the English clubs and the lesser clubs of Europe. Other than a few clubs from the top leagues such as Barcelona, Real Madrid, Bayern Munich, Juventus, etc., it became extremely difficult for clubs from other leagues to compete with English teams.

The revenue generated by European football has exceeded 25 billion euros (Deloitte, 2017) at the end of the $2015 / 2016$ season, which is more than the GDP of countries such as Bulgaria, Croatia, Slovakia and Slovenia (Eurostat, 2017). European football is drawing attention around the world, businessmen and companies which are all worth billions invest in European football and acquire teams. The football market is growing larger every season. The latest Premier League TV rights deal was worth about 5,6 billion euros, which will run for three years starting from 2016 (BBC, 2015), whereas the latest deal for Spanish La Liga was worth 2.65 billion euros for the same period (Total Sportek, 2016). The difference between the most paid and least paid clubs from the TV rights deal is about 55 million euros per season in English Premier League, whereas it is more than 90 million euros in Spanish La Liga (BBC, 2015; Total Sportek, 2016). Even though the top clubs in La Liga get paid as much as the top clubs in the Premier League, there is a huge gap between the lesser teams. Top clubs from the top leagues have the financial strength to compete with each other, but lesser clubs of top leagues and clubs from other leagues are losing their chance to compete because the gap in revenue generation is widening. 
Lorenz (1905) underlined the importance of knowing whether the current distribution of income is getting more equal or less and developed his famous Lorenz curve to illustrate the distribution of income. Lorenz curve has been used in several studies in the sports economic literature; however, it was used for measuring the level of competition not for distribution of income (Quirk \& Fort, 1997; Goossens, 2006; Di Betta \& Amenta, 2010). Each team's share in total points collected at the end of a season are used to construct a Lorenz curve in order to show the distribution of points collected.

The relationship between revenue sharing and competitive balance in different sports and leagues has been investigated in the literature several times. In North American professional leagues, revenue sharing is regulated; however, there is perfect competition in European football leagues in terms of revenue sharing. This study contributes to the literature in two ways: firstly, because European Union is a single market with free movement of capital, labor, goods, and services, so is the football market; however no studies are investigating the European football market as a whole in terms of revenue sharing. Secondly, due to the availability of more comprehensive data, the relationship between revenue generation and competitive balance is investigated more thoroughly compared to the previous studies in the literature.

This study constructs Lorenz curves to illustrate the change in revenue distribution between the top 5 leagues in the last 20 years. In addition to the construction of the Lorenz curves, the change in each league's share and the associated coefficient of variations (CV) are computed to exhibit the change in the distribution of income. Later, the change in revenue sharing is compared and contrasted with the change in the competitive balance between the clubs of the top 5 leagues. All data regarding the revenue generation are collected from Deloitte's "Annual Review of Football Finance" and "Money League" reports.

The findings of the study provide empirical evidence for the correlation between revenue generation and competitive power hence the answer to the question of whether money brings success or not in European football. This study aims to illustrate the worsening financial imbalance in European football and provide empirical evidence regarding its influence on competition using tools from the economics literature.

\section{Research Methodology and Design}

Competitive balance has been subject to numerous studies in the sports economics literature. It is a significant concern for all football leagues and tournaments hence a concern for all policymakers, fans, and all other stakeholders. Several methods have been suggested in the literature to measure competitive balance or imbalance in sports. The need for different methods arises from the various competition structures in different leagues and sports. 
This section provides a review of the methods used in the literature for measuring the competitive balance in professional sports. In the literature, the level of competition is investigated in three layers (Szymanski, 2001) Match Uncertainty, Seasonal Uncertainty and Championship Uncertainty. This study makes use of the same three-layered structure. Seasonal and championship uncertainty are the layers investigated in this study since they are associated with long-term factors hence revenue sharing.

It should be noted that most of the existing literature attempts to evaluate the competitive balance in leagues where the same number of teams play the same number of games every year. This study attempts to assess the change in competitive balance in knockout tournaments (elimination tournaments), so the number of teams and games varies over seasons; therefore, some of the methods used in the literature are not appropriate. Several methods, which are applicable, are chosen from the literature along with few other suggested methods, and they are all used to measure the change in competitive balance in the last two decades of European football.

Seasonal Imbalance

- Winning Percentage or Point Percentage

- Range of Win Percentage

- Standard Deviation of Win Percentage

- Gini Coefficient \& Lorenz Curve (Win Percentage)

- Standard Deviation Ratio

- Coefficient of Variation (CV)

- National Measure of Seasonal Imbalance (NAMSI)

- Herfindahl-Hirschman Index

- Relative Entropy

Championship Uncertainty

- Number of Championships per Team

- Top K Ranking

- Herfindahl-Hirschman Index

- Gini Coefficient \& Lorenz Curve (Percentage of League Championships)

- G-Index

Combined

- Competitive Balance Ratio (CBR)

- UEFA Associations' Club Coefficients Ranking

The methods for measuring competitive balance in the literature are listed above. Some of the methods are used more frequently than the others due to their ease of applicability or due to their characteristics. Seasonal imbalance and championship uncertainty are often misleading when used solely. Teams and players tend to under, 
or humans play over-perform from time to time since all sports. Measures that capture the effects of both seasonal and championship, imbalances are relatively more accurate than the others.

A selection of studies is presented in Table 1 to summarize the focus of the current literature. Revenue sharing and its influence on competitive balance have been studied several times for the North American professional leagues. There are strict regulations such as salary caps, match day revenue sharing, and the drafting system in North American leagues to maintain the competitive balance. European sports leagues do not have these kinds of regulations, which causes some teams to get richer than the others which eventually distorts the competitive balance. The trend in the change in competition in European sports leagues has not been investigated in detail the literature lacks empirical studies regarding this matter.

\subsection{Seasonal Imbalance}

Several methods have been used in the literature to compute the seasonal imbalance, as presented earlier. Some of these measures are quite easy to calculate and interpret whereas some are relatively harder. This section summarizes the methods used in the literature for measuring the seasonal imbalance

Winning Percentage and Point Percentage are perhaps the most common measures of competitive balance due to their ease of applicability and ease of interpretation. The percentage of games won at the end of a season is easy to compute, and in sports where teams can draw (like football), a draw is counted as a half win. The point percentage is the points collected by a team by the maximum number of available points. In knockout tournaments, the winner qualifies for the next round, and the loser gets eliminated. Playing more games means that a team has managed to qualify for the later rounds; therefore, it was more successful, but depending on the results, a team might have a lower win percentage after getting eliminated in the next round. Even though the win percentage was used in the study due to its popularity and applicability, it might be misleading in knockout tournaments. In Champions' League and UEFA (Europa League) Cup games, the primary focus is eliminating the opponent, not collecting points. This study investigates the competitive balance between leagues rather than teams; therefore, teams are assessed as representatives of leagues so that leagues can be compared with each other. Due to the availability of getting draws (1 point from a game whereas a win gives 3 points) in football, the percentage of points collected is a bit problematic. $A$ team can qualify for the next round with two draws ( 2 points), whereas a team might get eliminated by winning one game and losing one game ( 3 points) hence appearing more successful. Points Collected is used rather than the Percentage of Points in this study since the total points collected are not conclusive in knockout tournaments. However, it should be noted that this method might be misleading in some cases, just like in the winning percentage. 
An Empirical Study of Revenue Generation and Competitive Balance Relationship ...

Table 1. Competitive Balance and Revenue Sharing

\begin{tabular}{|c|c|c|c|}
\hline Study & Type of Sport & League & Method \\
\hline Rottenberg, 1956 & Baseball & North American & Number of Championships Won \\
\hline $\begin{array}{l}\text { El-Hodiri \& Quirck, } \\
1971\end{array}$ & Baseball & None & $\begin{array}{l}\text { No empirical investigation on } \\
\text { competition }\end{array}$ \\
\hline Sloane, 1976 & $\begin{array}{l}\text { Baseball, Basketball, } \\
\text { Football, Ice Hockey, } \\
\text { Soccer, Cricket }\end{array}$ & None & $\begin{array}{l}\text { No empirical investigation on } \\
\text { competition }\end{array}$ \\
\hline Vrooman, 1995 & $\begin{array}{l}\text { Baseball, Basketball, } \\
\text { Football, Ice Hockey }\end{array}$ & North American & $\begin{array}{l}\text { Standard Deviation of Win } \\
\text { Percentage, Standard Deviation } \\
\text { Ratio }\end{array}$ \\
\hline Horowitz, 1997 & Baseball & North American & Relative Entropy \\
\hline $\begin{array}{l}\text { Dobson \& } \\
\text { Goddard, } 1998\end{array}$ & Soccer & English & $\begin{array}{l}\text { Performance Score (score based } \\
\text { on the ranking at the end of the } \\
\text { season) }\end{array}$ \\
\hline Depken, 1999 & Baseball & North American & $\begin{array}{l}\text { Herfindahl-Hirschman Index } \\
\text { (wins) }\end{array}$ \\
\hline Szymanski, 2001 & Soccer & English & $\begin{array}{l}\text { Standard Deviation of Win } \\
\text { Percentage, Top K Ranking }\end{array}$ \\
\hline $\begin{array}{l}\text { Hall, Szymanski \& } \\
\text { Zimbalist, } 2002\end{array}$ & Baseball, Soccer & $\begin{array}{l}\text { North } \\
\text { American, } \\
\text { English } \\
\end{array}$ & Winning Percentage \\
\hline Humphreys, 2002 & Baseball & North American & Competitive Balance Ratio (CBR) \\
\hline $\begin{array}{l}\text { Buzzacchi, } \\
\text { Szymanski \& } \\
\text { Valletti, } 2003\end{array}$ & $\begin{array}{l}\text { Baseball, Basketball, } \\
\text { Ice Hockey, Soccer }\end{array}$ & $\begin{array}{l}\text { North } \\
\text { American, } \\
\text { Italian, English, } \\
\text { Belgian } \\
\end{array}$ & $\begin{array}{l}\text { Top K Ranking, A Gini like } \\
\text { dynamic coefficient based on top } \\
\text { K rankings }\end{array}$ \\
\hline $\begin{array}{l}\text { Schmidt \& Berri, } \\
2003\end{array}$ & Baseball & North American & Gini Coefficient and Lorenz Curve \\
\hline $\begin{array}{l}\text { Dobson \& } \\
\text { Goddard, } 2004\end{array}$ & Soccer & English & $\begin{array}{l}\text { Standard Deviation of Win } \\
\text { Percentage, Trends in Winning } \\
\text { Probabilities }\end{array}$ \\
\hline $\begin{array}{l}\text { Palomino \& } \\
\text { Sakovics, } 2004\end{array}$ & $\begin{array}{l}\text { Baseball, Basketball, } \\
\text { Football, Ice Hockey, } \\
\text { Soccer }\end{array}$ & $\begin{array}{l}\text { North } \\
\text { American, } \\
\text { English }\end{array}$ & Winning Probabilities \\
\hline Goosens, 2006 & Soccer & $\begin{array}{l}\text { Major } \\
\text { European } \\
\text { Leagues } \\
\end{array}$ & $\begin{array}{l}\text { Winning Percentage, Top K } \\
\text { Ranking, Lorenz curves, and Gini } \\
\text { coefficients }\end{array}$ \\
\hline Késenne, 2006 & Applicable to all & None & $\begin{array}{l}\text { No empirical investigation on } \\
\text { competition }\end{array}$ \\
\hline $\begin{array}{l}\text { Chang \& Sanders, } \\
2009\end{array}$ & Baseball & None & $\begin{array}{l}\text { No empirical investigation on } \\
\text { competition }\end{array}$ \\
\hline Maxcy, 2009 & Baseball & North American & $\begin{array}{l}\text { Standard Deviation of Win } \\
\text { Percentage }\end{array}$ \\
\hline Vrooman, 2009 & $\begin{array}{l}\text { Baseball, Basketball, } \\
\text { Football, Ice Hockey }\end{array}$ & North American & $\begin{array}{l}\text { Number of Championships Won } \\
\text { per Team, Winning Percentage }\end{array}$ \\
\hline
\end{tabular}


The Standard Deviation and Range of Standard Deviation of Win and Point Percentages are also used as indicators of competition in the literature. Standard deviation, when used alone, might provide inaccurate information to evaluate the competitive balance; therefore, the coefficient of variation is used instead.

Coefficient of Variation (CV) is a statistical measure for variability. It has been used by Sloane (1976) and many others in the literature to measure competitive balance in a season.

$$
C V=\sigma / \mu
$$

The ratio of a sample's standard deviation to its mean gives the coefficient of variation. It has been used for winning percentages and points collected to measure the level of competition. The coefficient of variation is easy to interpret; as the value gets larger the level of competition decreases and vice versa. Using CV instead of winning percentages or points collected provide more credible findings due to CV's ability offsets the effects of seasonal variations in the overall winning percentages and points collected.

Gini Coefficient and Lorenz Curve are also used for measuring the level of competition. The percentage of points collected by each team at the end of a season is used to construct a Lorenz curve and calculate the Gini coefficient associated with it. The number of teams from each country and the number of games played between teams from different leagues change every season in Champions' League and UEFA (Europa League) Cup, so constructing a Lorenz curve and calculating a Gini coefficient would be inconsistent.

The ratio of the actual standard deviation to an idealized standard deviation is called the Standard Deviation Ratio. Quirk and Fort (1995) proposed 0.5/VN as the idealized standard deviation, where $\mathrm{N}$ is the number of games played in a season. The standard deviation ratio is relatively a better measure for competition than the standard deviation itself; however, it is not used in the study as well since Competitive Balance Ratio (CBR) is used, a method which makes use of the standard deviation ratio.

Goossens (2006) argues that due to the differences in the number of teams in leagues and due to the changes in the number of teams in leagues, the standard deviation is biased. Goossens proposes an alternative measure for measuring seasonal imbalance, which is the National Measure of Seasonal Imbalance (NAMSI). Similar to the standard deviation ratio, NAMSI constructs a ratio using the possible minimum and maximum standard deviations, which might occur in a season instead of using a proposed idealized standard deviation. NAMSI is not widely recognized in the literature; hence, it was not used in this study.

Horowitz (1997) uses Relative-Entropy measure from the information theory to measure the competitive balance for baseball, whereas Depken (1999) computes the Herfindahl-Hirschman Index for the Major League Baseball using the number of wins for output and market share. Concentration Ratio and Herfindahl-Hirschman index 
are two measures for assessing the degree of competition in an industry, as illustrated by Behname (2012) are not used to assess the level of competition; however, the concentration ratio is used to demonstrate the revenue shares of the football leagues in Europe.

\subsection{Championship Uncertainty}

Measuring the imbalance within a season is important, but it provides insights about the short-term competition. Even though it appears like there is competition within a season, the long-term winner might be the same all the time. The same teams competing for the title every season (as in the case of almost all European leagues) means that there is a competitive imbalance even if the short-term competition is fierce. Several methods have been used in the literature to measure the championship uncertainty.

Number of Championships per Team, used in this study, is easy to calculate and straight forward measure to illustrate championship uncertainty. The number of champions from each league is used to demonstrate the competitive balance in inter-European competitions.

Top K Ranking is similar to the number of different champions, which investigates the number of different teams that managed to finish in top k rankings. In this study, the Last 16 of Champions' League and UEFA (Europa League) Cup are used as top $k$ rankings. The number of teams from each league that has managed to qualify for the Last 16 every season is used as an indicator of performance.

Herfindahl-Hirschman Index is used in the literature regarding the distribution of championships. In this study, the concentration ratio regarding the distribution of cups won by each league is computed instead of the Herfindahl-Hirschman index. Since teams from three or four leagues win almost all of the cups, the concentration ratio is enough to emphasize the imbalance in European football.

Gini Coefficient and Lorenz Curve for the distribution of league championships are also used in the literature. As mentioned earlier, championships are won by teams from only a few different leagues, and the study investigates a two-decade period meaning that there are forty cups to be won hence to be distributed among the leagues. Lorenz curve and Gini coefficient were not estimated for this short time.

Buzzacchi and his colleagues (2003) propose an alternative measure that emphasizes between seasons' competitive balance rather than within seasons' competitive balance. Authors distinguish between closed (North American) and open (European) leagues while constructing their Gini-type index making use of top k rank, which they call the G-Index.

\subsection{Combined}

Seasonal Imbalance (short-term) and Championship Uncertainty (long-term) both provide valuable insights regarding the competitive balance in sports; however, it is 
often misleading to investigate the short-term and long-term trends separately. To overcome the ambiguity, methods are suggested which make use of both short term and long-term trends to determine the competitive balance.

Competitive Balance Ratio (CBR) is a dynamic measure of competition proposed by Humphreys (2002). Making use of the winning percentage standard deviations within seasons and between seasons, a ratio is constructed which captures the effects of both seasonal and championship uncertainty. CBR takes a value between zero and one, and as the value gets closer to zero, it is an indication of competitive imbalance, whereas as it gets closer to one, it means the competitive balance is increasing. CBR is easy to compute and interpret, and it has been used in this study due to its effectiveness in capturing both between-seasons and within-seasons competition.

$$
\begin{aligned}
& \llbracket S D{ }_{-}(w t, i)=V\left(\Sigma_{-}(s=1)^{\wedge} S_{\text {w.: }}\left(w_{-}(i, s)-w_{-} i\right)^{\wedge} 2\right) / S
\end{aligned}
$$

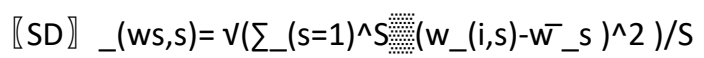

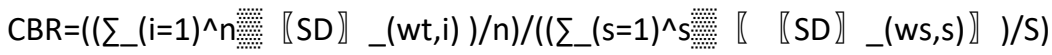

UEFA Associations' Club Coefficients is the ranking system used by UEFA, the governing body of European football. UEFA ranks each association by the number of points collected in international competitions in the past five seasons. UEFA rankings are used to decide the number of teams from each association who will participate in European competitions. These points are calculated separately for Champions' League and UEFA (Europa League) Cup, which makes it possible to investigate the competitive balance in different tournaments separately.

\section{Results and Findings}

One of the few exceptions to the triumph of money over will is the Premier League title won by Leicester City in the 2015/2016 season. Football has become less about competition and ambition but more about power, money, and domination. Billioneuro TV rights deals and sponsorship agreements have turned football clubs into money-making entities. In 20 years, from 1996/1997 to 2015/2016, the total revenue generated by the top 5 leagues in Europe has increased from 2497 million euros to 13416 (Deloitte, 2017).

Figure 1 plots the standard deviation of revenue shares between the seasons $1996 / 1997$ and 2015/2016. The fitted values illustrate the trend in the standard deviation, which is increasing; hence, the distribution of income is getting more uneven over the past two decades. Table 2 presents the revenue data for Europe's top 5 leagues over the last two decades which are later used to construct Lorenz Curves in Figure 2. A Lorenz curve graphically represents the income inequality by plotting percentiles of the population and income. 
An Empirical Study of Revenue Generation and Competitive Balance Relationship ...

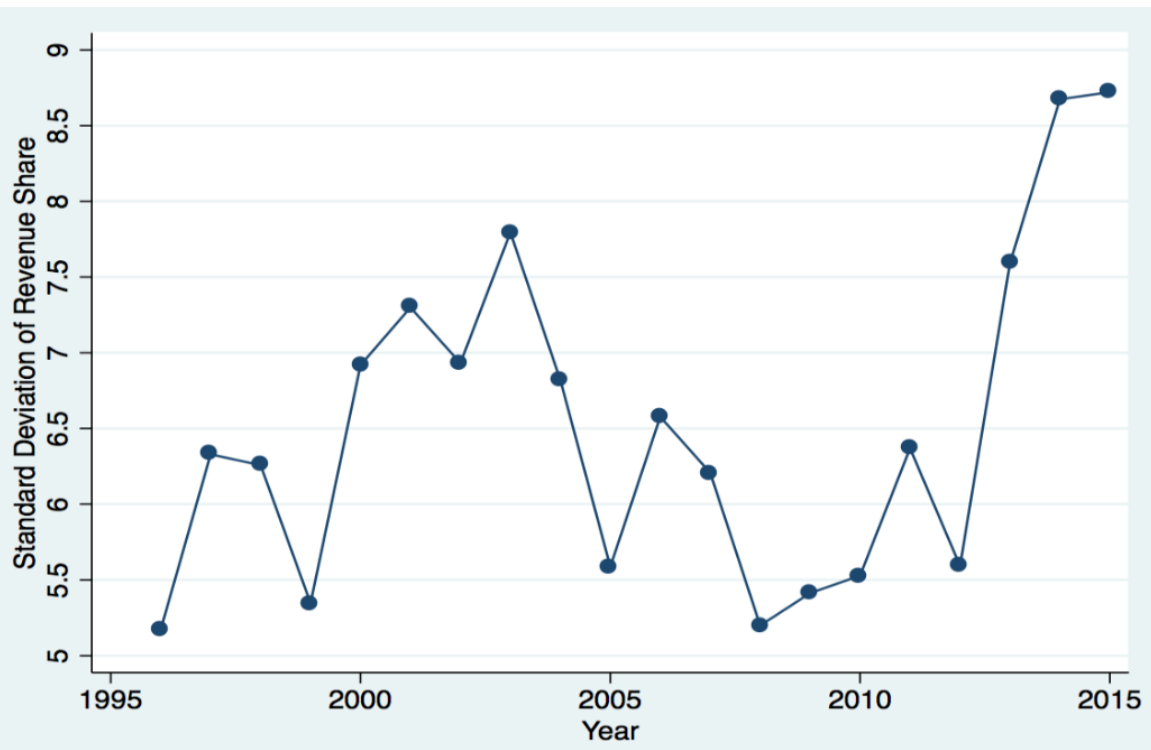

Figure 1. Variation in Revenue Shares

Table 2. Revenue Shares for Each League

\begin{tabular}{cccccc}
\hline Season & England & Italy & Germany & Spain & France \\
\hline $1996 / 1997$ & 27.43 & 22.07 & 17.78 & 20.99 & 11.73 \\
\hline $1997 / 1998$ & 30.34 & 22.03 & 19.29 & 17.39 & 10.95 \\
\hline $1998 / 1999$ & 30.84 & 21.51 & 17.38 & 18.43 & 11.84 \\
\hline $1999 / 2000$ & 29.14 & 22.81 & 16.28 & 17.26 & 14.51 \\
\hline $2000 / 2001$ & 32.55 & 21.47 & 18.39 & 14.13 & 13.46 \\
\hline $2001 / 2002$ & 33.43 & 19.46 & 19.96 & 14.85 & 12.30 \\
\hline $2002 / 2003$ & 32.81 & 18.76 & 20.30 & 15.52 & 12.62 \\
\hline $2003 / 2004$ & 34.71 & 18.47 & 18.58 & 16.73 & 11.50 \\
\hline $2004 / 2005$ & 32.09 & 19.81 & 20.08 & 16.72 & 11.31 \\
\hline $2005 / 2006$ & 30.53 & 19.54 & 18.29 & 17.72 & 13.93 \\
\hline $2006 / 2007$ & 32.41 & 15.17 & 19.66 & 18.91 & 13.86 \\
\hline $2007 / 2008$ & 31.59 & 18.39 & 18.61 & 18.61 & 12.80 \\
\hline $2008 / 2009$ & 29.28 & 18.81 & 19.83 & 18.89 & 13.19 \\
\hline $2009 / 2010$ & 29.54 & 18.26 & 19.83 & 19.59 & 12.78 \\
\hline $2010 / 2011$ & 29.34 & 18.12 & 20.37 & 20.04 & 12.13 \\
\hline $2011 / 2012$ & 31.51 & 16.94 & 20.19 & 19.12 & 12.24 \\
\hline $2012 / 2013$ & 30.04 & 17.10 & 20.58 & 19.05 & 13.23 \\
\hline $2013 / 2014$ & 34.48 & 15.04 & 20.13 & 17.10 & 13.25 \\
\hline $2014 / 2015$ & 36.52 & 14.85 & 19.84 & 17.03 & 11.76 \\
\hline $2015 / 2016$ & 36.26 & 14.29 & 20.21 & 18.16 & 11.07 \\
\hline Average & $\mathbf{3 1 . 7 4}$ & $\mathbf{1 8 . 6 4}$ & $\mathbf{1 9 . 2 8}$ & $\mathbf{1 7 . 8 1}$ & $\mathbf{1 2 . 5 2}$ \\
\hline
\end{tabular}

Source: Compiled by authors from Deloitte reports 
Table 2 provides valuable insights regarding the change in revenue sharing structure among the top 5 leagues of Europe. Perhaps the most striking change in the last two decades is the increase in English Premier League's share. The premier league has managed to increase its share from $27.43 \%$ to $36.26 \%$ in twenty years. Only one other league has managed to increase its share from 1996/1997 to $2015 / 2016$ which is German Bundesliga 1. Its share has increased from $17.78 \%$ to $20.12 \%$.

Another significant finding which can be deducted from the table is the change in the order of the leagues concerning revenue generation. English Premier League has always been at the top, and French Ligue 1 has always been at the bottom in terms of revenue generation; however, Italian, German, and Spanish leagues have changed rankings list several times. In 1996/1997, Italian Serie A was the second richest league that enjoyed its reign in second place till the 2002/2003 season, and meanwhile, Bundesliga and La Liga have kept changing rankings. Starting with the 2003/2004 season, German Bundesliga became the 2nd richest league in Europe and kept this title till the $2015 / 2016$ season, with the $2005 / 2006$ season being the only exception where Serie A took the 2 nd place.

The average revenue shares of the twenty years are in the last row of the table, even though Italy averaged the third-highest revenue there is almost a $4 \%$ gap between Serie A and La Liga in the recent years. It is important to draw attention to the dramatic decrease in Serie A's revenue from 2005/2006 to 2006/2007. The Italian Football Scandal in 2006 caused Juventus FC to be relegated to the lower division as well as numerous other sanctions to other major teams such as AC Milan, ACF Fiorentina, and S.S. Lazio which caused the league to lose great reputation and value (BBC, 2006). Serie A's share decreased by almost $5 \%$ in a single season and was never able to recover.

Table 3 provides the average revenue growth rates for periods 1 and 2 for each league. First, it should be mentioned that all of the leagues have grown much faster in the first period than the second period. The most unexpected finding presented in the table is the French Ligue 1's average growth rate in the first period, even though the French league had the lowest share in the first period it was the fastestgrowing one. The French league couldn't preserve the high growth rate and failed to converge to the other leagues. The highest average growth rates in the second period belong to English Premier League and German Bundesliga 1 and the lowest to Italian Serie A and French Ligue 1. Spanish La Liga had the lowest average growth rate in period 1 but the most consistent overall since it has the smallest decrease from period 1 to period 2 . The revenues generated by each of the top 5 leagues have grown significantly over the last two decades; however, some grew faster than the others. English and German leagues became relatively richer than the others.

\section{Table 3. Revenue Share Growth Rates}

\begin{tabular}{cccccc}
\hline Average growth rates & England & France & Germany & Italy & Spain \\
\hline $\mathbf{1}^{\text {st }}$ Period & 0.131 & 0.146 & 0.123 & 0.102 & 0.095 \\
\hline $\mathbf{2}^{\text {nd }}$ Period & 0.097 & 0.052 & 0.086 & 0.048 & 0.078 \\
\hline
\end{tabular}


An Empirical Study of Revenue Generation and Competitive Balance Relationship ...

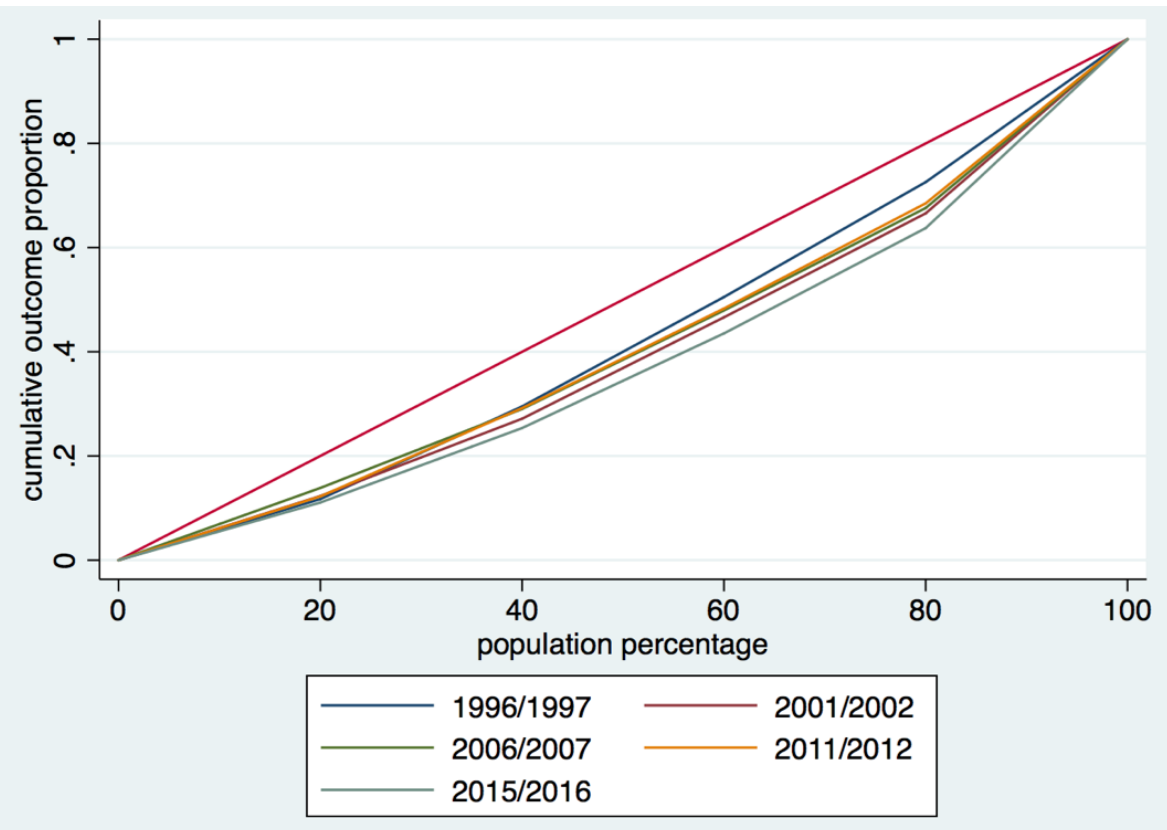

Figure 2. Lorenz Curves

Figure 2 illustrates the data in Table 1 in the form of Lorenz curves for every five years. As can be seen from the figure revenue sharing has deteriorated from $1996 / 1997$ to $2015 / 2016$. The sum of the lowest two leagues' share has decreased from $29.52 \%$ to $25.36 \%$, whereas the sum of the lowest three league's share has dropped to $43.52 \%$ from $50.50 \%$. It is important to mention that the second most unequal generation of revenue was in the 2001/2002 season which is the first Lorenz Curve in the figure after the most equally distributed season. Later the revenue distribution became closer in 2006/2007 but gradually deteriorated till 2015/2016, where it hit rock bottom. The Gini Coefficient for the $1996 / 1997$ season is 0.142 , whereas 0.225 for the $2015 / 2016$ season, which indicates the deterioration in revenue distribution in European football.

Tables 4, 5, 7, and 8 present the points collected in the matches played between the clubs from the top 5 leagues and their win percentages against each other in Champions League and UEFA (Europa League) Cup, including the UEFA Cup Winners' Cup. The change in revenue distribution and the change in points collected will be compared and contrasted to investigate the correlation between the two.

In the Champions' League, most points have been collected by the Spanish teams in the last twenty years thanks to Real Madrid and FC Barcelona, who have collected 380 points out of the 637 points collected by the Spanish teams. Spanish teams lead in total points collected during both periods; however, in win rates, they have lost the first place to the English clubs in the second period. Even though Real Madrid 
and FC Barcelona have increased their aggregate winning percentages from period one to period two (from 61.6\% to 64.45) the overall rates have decreased for Spanish teams. In period one, the win rate for the rest of the Spanish teams was $52.8 \%$, whereas it is $43 \%$ in period two which means a decrease of almost $10 \%$.

Table 4. Points Collected in Champions' League

\begin{tabular}{|c|c|c|c|c|c|}
\hline Season & England & France & Germany & Italy & Spain \\
\hline $1996 / 1997$ & 0 & 0 & 18 & 6 & 3 \\
\hline $1997 / 1998$ & 8 & 9 & 9 & 9 & 14 \\
\hline $1998 / 1999$ & 15 & 4 & 8 & 6 & 7 \\
\hline $1999 / 2000$ & 29 & 8 & 20 & 31 & 40 \\
\hline $2000 / 2001$ & 34 & 15 & 28 & 16 & 47 \\
\hline $2001 / 2002$ & 43 & 13 & 39 & 13 & 48 \\
\hline $2002 / 2003$ & 36 & 18 & 21 & 43 & 57 \\
\hline $2003 / 2004$ & 23 & 17 & 6 & 14 & 30 \\
\hline $2004 / 2005$ & 35 & 14 & 14 & 34 & 24 \\
\hline $2005 / 2006$ & 23 & 12 & 12 & 24 & 49 \\
\hline $2006 / 2007$ & 38 & 8 & 14 & 26 & 20 \\
\hline $2007 / 2008$ & 48 & 11 & 8 & 12 & 32 \\
\hline $2008 / 2009$ & 37 & 7 & 15 & 22 & 21 \\
\hline $2009 / 2010$ & 21 & 16 & 17 & 32 & 30 \\
\hline $2010 / 2011$ & 31 & 8 & 26 & 16 & 24 \\
\hline $2011 / 2012$ & 39 & 13 & 30 & 28 & 28 \\
\hline $2012 / 2013$ & 14 & 8 & 49 & 8 & 30 \\
\hline $2013 / 2014$ & 37 & 9 & 26 & 22 & 45 \\
\hline $2014 / 2015$ & 16 & 16 & 22 & 13 & 42 \\
\hline $2015 / 2016$ & 23 & 14 & 26 & 20 & 46 \\
\hline $1996 / 1997$ to $2005 / 2006$ & 246 & 110 & 175 & 196 & 319 \\
\hline $2006 / 2007$ to $2015 / 2016$ & 304 & 110 & 233 & 199 & 318 \\
\hline Total & 550 & 220 & 408 & 395 & 637 \\
\hline
\end{tabular}

Source: Compiled by authors from UEFA

Table 5. Winning Percentages in Champions' League

\begin{tabular}{cccccc}
\hline Period & England & France & Germany & Italy & Spain \\
\hline $\mathbf{1 9 9 6 / 1 9 9 7}$ to $\mathbf{2 0 0 5 / 2 0 0 6}$ & 53.47 & 45.21 & 43.75 & 46.73 & 57.11 \\
\hline $\mathbf{2 0 0 6 / 2 0 0 7}$ to $2015 / 2016$ & 63.37 & 35.27 & 53.87 & 47.08 & 56.13 \\
\hline
\end{tabular}

Winning percentages and points collected provide valuable evidence; however, what matters at the end of the day is the number of trophies and championships won. Number of Championships per Team and Top K Ranking are two key measures of competition which are often used in the literature.

Table 6 presents the number of teams from the top 5 leagues who were able to qualify for the Last 16 and onwards in the Champions' League. First of all, it should be mentioned that teams from the top 5 leagues expanded their slot share significantly from period one to period two, meaning that they have increased their supremacy over the teams from other leagues. The competitive balance between 
the teams of the top 5 leagues and the teams from other leagues is another subject that needs a detailed investigation, which and will be mentioned in the limitations and suggestions section of this study.

Table 6. Champions' League Slots and Titles

Champions League

\begin{tabular}{lccccc}
\hline \multicolumn{7}{c}{$\mathbf{1 9 9 6 / 1 9 9 7 - 2 0 0 5 / 2 0 0 6}$} \\
\hline England & Last $\mathbf{1 6}$ & Quarter Finals & Semi-Finals & Finals & Title \\
\hline Germany & 14 & 16 & 8 & 3 & 2 \\
\hline Italy & 18 & 11 & 6 & 4 & 2 \\
\hline France & 10 & 15 & 8 & 5 & 1 \\
\hline Spain & 22 & 6 & 2 & 1 & \\
\hline \multicolumn{7}{c}{$\mathbf{1 9 9 6 / 1 9 9 7 - 2 0 0 5 / 2 0 0 6}$} & & 4 \\
\hline England & 33 & Quarter Finals & Semi-Finals & Finals & Title \\
\hline Germany & 22 & 23 & 13 & 6 & 2 \\
\hline Italy & 23 & 12 & 8 & 4 & 1 \\
\hline France & 15 & 7 & 3 & 3 & 2 \\
\hline Spain & 31 & 8 & 1 & & \\
\hline
\end{tabular}

So far, Winning Percentage, Points Collected, Number of Championships per Team, and Top K Ranking have been presented to display the competitive balance, and they provided valuable information regarding the change in competition in European football, but there is still room for further investigation. UEFA Associations' Club Coefficients provide valuable insights regarding the competitive balance. The coefficients for each league can be used as an indicator of performance. Each association collects points from Champions' League and UEFA (Europa League) Cup separately. Figure 3 plots the coefficient of variations of points (used for calculating UEFA Associations' Club Coefficients), collected by the top 5 leagues in the Champions' League. The figure illustrates that the coefficient of variation has been increasing in the Champions' League over the last few decades means that the imbalance is getting worse.

As mentioned earlier, another measure for competitive balance, used in the literature, is the Competitive Balance Ratio (CBR) (Humphreys, 2002). CBR for the Champions' League in the first period (1996/1997 - 2005/2006) is 0.42 and in the second period $(2006 / 2007-2015 / 2016)$ is 0.22 , indicating that competitive balance has decreased from period 1 to period 2 . Like the other methods used for measuring the competitive balance in Champions' League, CBR has also provided empirical evidence to argue that the level of competition in the Champions' League is decreasing. 


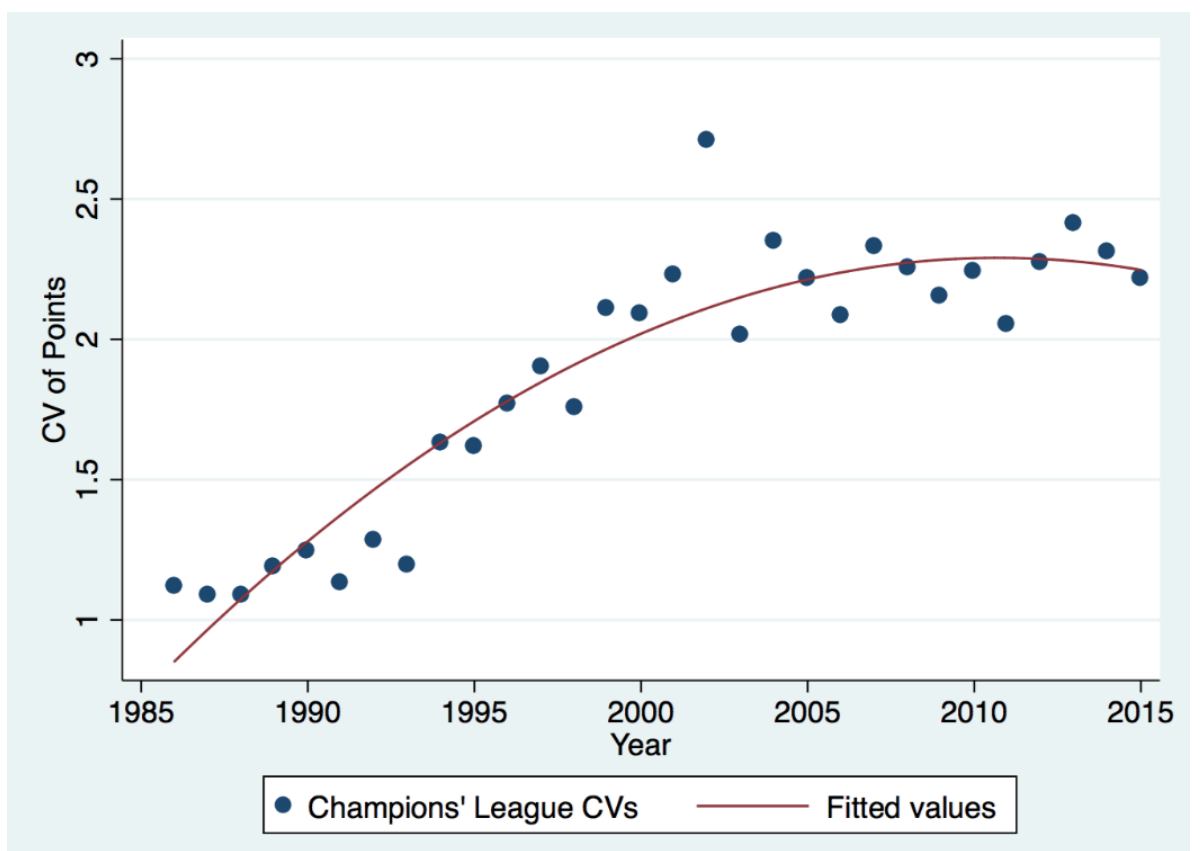

\section{Figure 3. Coefficient of Variation of Points Collected in Champions' League}

The following section provides a similar analysis for the UEFA (Europa League) Cup, which will investigate the change in the competitive balance of the tournament.

In UEFA Cup and UEFA Europa League competitions, most points are again collected by the Spanish teams, as in the case of Champions' League. English teams performed slightly worse in the second period. They have collected 19 points less in the second period; however, $47 \%$ of this variation can be explained by the decrease in the number of English teams competing in the UEFA Cup and Europa League. Again, the French teams are at the bottom collecting the least points. The German teams follow them; however, an increase in points collected by the German teams is present as in the case of Champions' League. Also, it should be noted that German teams managed to collect more points with fewer teams in the second period (51 in first, 41 in second), which reflected on the win rates. French and Italian teams have collected fewer points in the second period when compared to the first which coincides with the change in their share in total revenue from the first ten years to the second. It is important to mention that in the first period, 59 French teams were competing in UEFA Europa League (including Cup Winners' Cup), and in the second period there were 43 , so a decrease in points was not unexpected, but their win rate has decreased drastically as well.

Spanish teams dominated the UEFA Europa League between 2006/2007 and $2015 / 2016$ both in points collected and win percentage. They've collected almost 
$50 \%$ more points than the 2 nd best performer Germany and their win rate is more than $60 \%$. The domination against the other four big leagues enabled Spanish teams to win the UEFA Europa League six times out of the possible ten in this period (Sevilla FC 4 times, Atlético Madrid 2 times).

Table 7. Points Collected in UEFA Cup and UEFA Europa League

\begin{tabular}{|c|c|c|c|c|c|}
\hline Season & England & France & Germany & Italy & Spain \\
\hline $1996 / 1997$ & 7 & 22 & 16 & 13 & 14 \\
\hline $1997 / 1998$ & 24 & 10 & 11 & 21 & 14 \\
\hline 1998/1999 & 14 & 9 & 1 & 27 & 16 \\
\hline $1999 / 2000$ & 27 & 18 & 15 & 14 & 23 \\
\hline $2000 / 2001$ & 8 & 4 & 4 & 18 & 22 \\
\hline $2001 / 2002$ & 6 & 11 & 5 & 10 & 1 \\
\hline $2002 / 2003$ & 8 & 3 & 4 & 0 & 7 \\
\hline $2003 / 2004$ & 8 & 18 & 1 & 3 & 12 \\
\hline $2004 / 2005$ & 3 & 3 & 4 & 9 & 8 \\
\hline $2005 / 2006$ & 11 & 22 & 19 & 9 & 17 \\
\hline $2006 / 2007$ & 14 & 9 & 14 & 16 & 21 \\
\hline $2007 / 2008$ & 8 & 0 & 9 & 4 & 7 \\
\hline $2008 / 2009$ & 7 & 3 & 23 & 10 & 7 \\
\hline $2009 / 2010$ & 18 & 9 & 13 & 13 & 10 \\
\hline $2010 / 2011$ & 6 & 8 & 11 & 4 & 16 \\
\hline $2011 / 2012$ & 0 & 4 & 5 & 7 & 41 \\
\hline $2012 / 2013$ & 15 & 11 & 5 & 18 & 0 \\
\hline $2013 / 2014$ & 4 & 4 & 6 & 10 & 10 \\
\hline $2014 / 2015$ & 5 & 3 & 9 & 14 & 15 \\
\hline $2015 / 2016$ & 20 & 7 & 9 & 6 & 24 \\
\hline $1996 / 1997$ to $2005 / 2006$ & 116 & 120 & 80 & 124 & 134 \\
\hline $2006 / 2007$ to $2015 / 2016$ & 97 & 58 & 104 & 102 & 151 \\
\hline Total & 213 & 178 & 184 & 226 & 285 \\
\hline
\end{tabular}

Table 8. Win Percentages in UEFA Cup and UEFA Europa League

\begin{tabular}{cccccc}
\hline Period & England & France & Germany & Italy & Spain \\
\hline $\mathbf{1 9 9 6 / 1 9 9 7}$ to $\mathbf{2 0 0 5 / 2 0 0 6}$ & 53.52 & 52.78 & 34.57 & 51.69 & 53.23 \\
\hline $\mathbf{2 0 0 6 / 2 0 0 7}$ to $\mathbf{2 0 1 5 / 2 0 1 6}$ & 49.33 & 39.81 & 44.89 & 52.82 & 61.67 \\
\hline
\end{tabular}

In the first period, four of the top 5 leagues (all except France) managed to win a UEFA Cup or UEFA Europa League, whereas only English and Spanish teams managed to win in the second. Even though English teams appear to be performing worse, they've managed to win a UEFA Europa League.

Figure 4 illustrates the change in competition in the UEFA Cup and the UEFA Europa League using the coefficient of variation of points, as Figure 3 did for Champions' League. Concerning Associations' Club Coefficient points, the competitive balance in UEFA Cup and UEFA Europa League did not deteriorate much, as can be seen from 
the figure. However, regarding the Number of Different Champions or in terms of Top K Rankings, some leagues dominated the others.

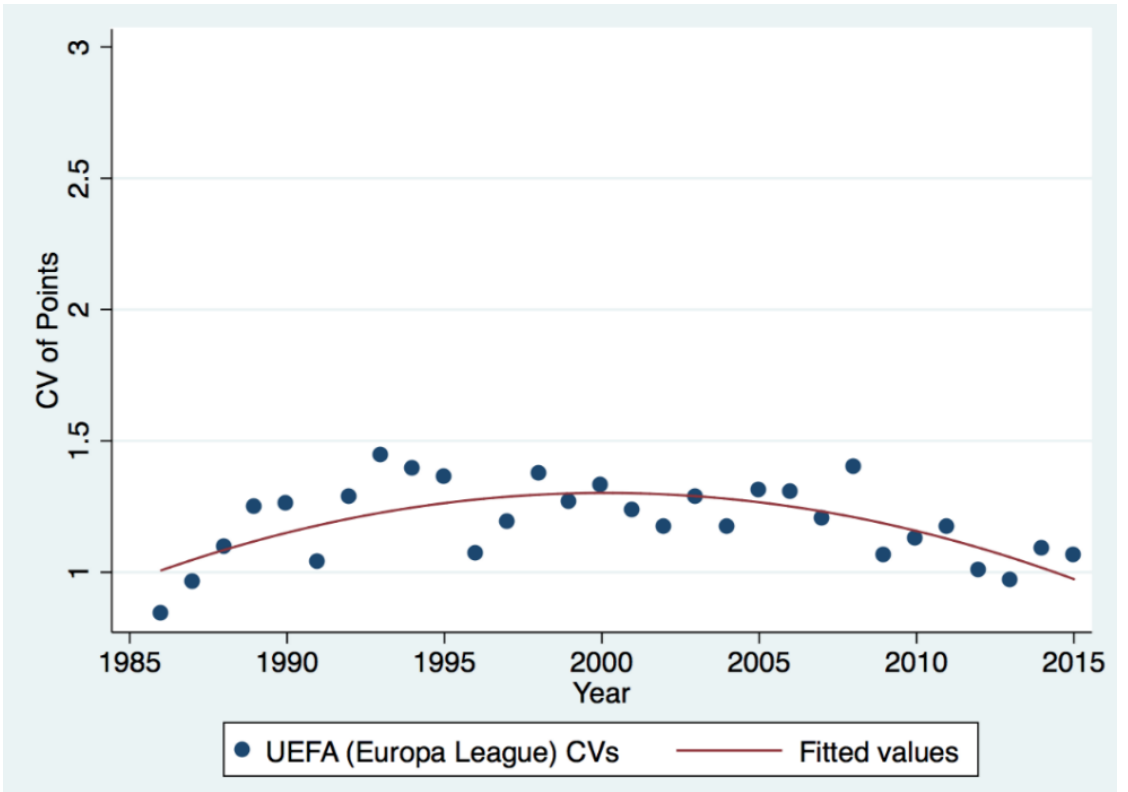

Figure 4. Coefficient of Variation of Points Collected in UEFA (Europa League)

Table 9 is the projection of Table 6 for the UEFA Europa League and UEFA Cup including the Cup Winners' Cup. It provides the Number of Championships per Team and Top 16 Ranking. Unlike in the Champions' League, teams from the top 5 leagues failed to qualify more to the final stages in the UEFA Europa League and Cup in the second period. In the first period, the top 5 league teams acquired $60.5 \%, 76.9 \%$, and $76.9 \%$ of the Quarter-Finals, Semi-Finals, and Final slots, respectively, whereas their shares decreased to $56.2 \%$ and $65 \%$ and $60 \%$ in the second period. Teams from other leagues have managed to compete with the teams from the top 5 leagues.

Finally, Competitive Balance Ratio (CBR) for periods 1 and 2 is presented to inspect the change in competitive balance in UEFA Cup and UEFA Europa League. The CBR has changed from 0.43 to 0.39 from period 1 to period 2 . There is a slight drop in the competitive balance ratio indicating that the competitive balance is deteriorating.

So far, evidence regarding the unequal distribution of revenue in European football and its influence on competitive balance has been provided separately. Figure 5 plots the coefficient of variation of the Associations' Club Coefficient points of top 5 leagues and the coefficient of variation for revenue distribution between 1996/1997 and 2015/2016 seasons. The figure illustrates the relationship between revenue distribution and competitive balance graphically. 
An Empirical Study of Revenue Generation and Competitive Balance Relationship ...

Table 9. UEFA (EUROPA LEAGUE) Cup Slots and Titles

\begin{tabular}{lccccc}
\multicolumn{7}{c}{ UEFA (Europe League) Cup } \\
\hline \multicolumn{7}{c}{ 1996/1997-2005/2006 } \\
\hline England & Last 16 & Quarter Finals & Semi-Finals & Finals & Title \\
\hline Germany & 16 & 12 & 8 & 4 & 2 \\
\hline Italy & 24 & 7 & 5 & 3 & 1 \\
\hline France & 26 & 14 & 12 & 5 & 3 \\
\hline Spain & 29 & 10 & 5 & 3 & \\
\hline \multicolumn{7}{c}{$\mathbf{1 9 9 6 / 1 9 9 7 - 2 0 0 5 / 2 0 0 6}$} & & 2 \\
\hline England & 20 & Quarter Finals & Semi-Finals & Finals & Title \\
\hline Germany & 18 & 8 & 4 & 3 & 1 \\
\hline Italy & 15 & 12 & 5 & 1 & \\
\hline France & 11 & 5 & 4 & & \\
\hline Spain & 21 & 4 & 13 & 8 & 6 \\
\hline
\end{tabular}

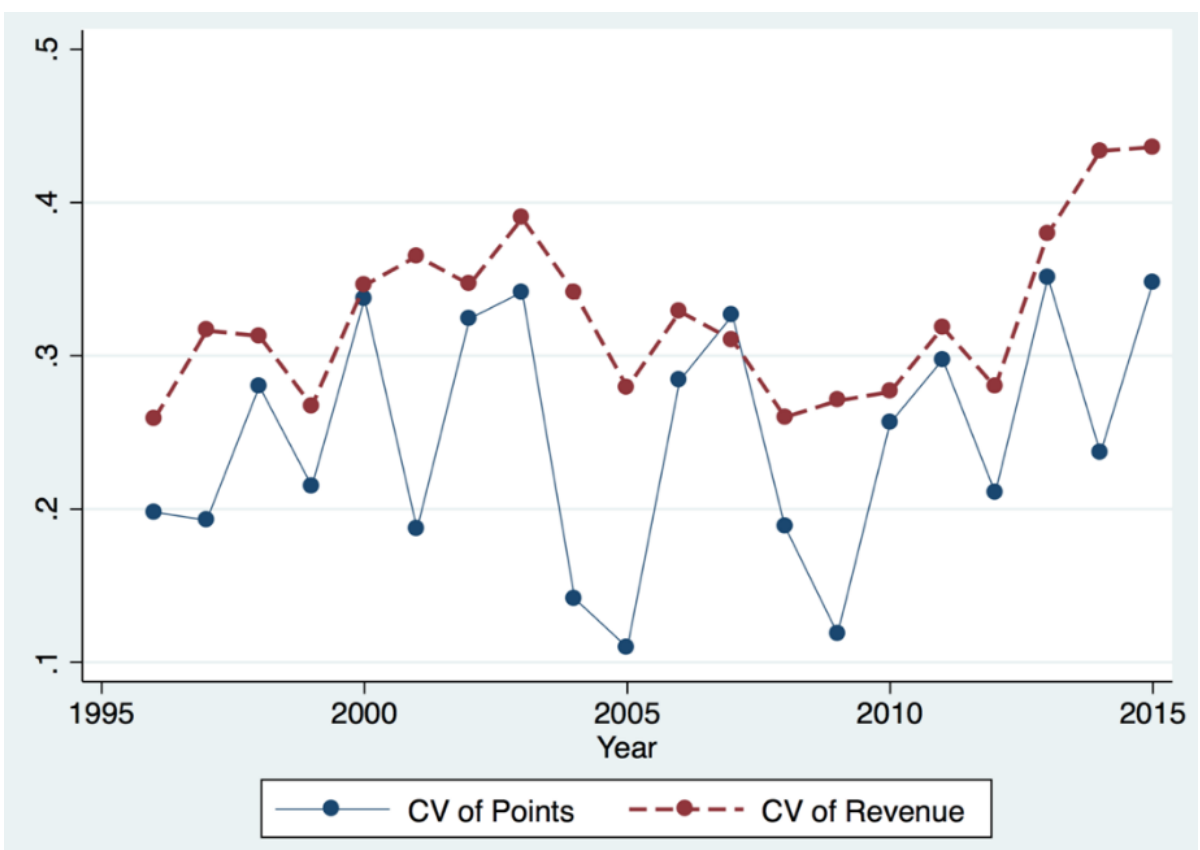

Figure 5. Coefficient of Variation of Points Against Revenue Shares 


\section{Discussion and Conclusion}

If European football were an economy, it would have been the fastest growing economy of Europe, with an average of $7 \%$ annual growth rate in the past decade (Eurostat, 2017; Deloitte, 2017). Funds from all over the world have been flowing to European football, and the market has grown enormously. More than half of this gigantic market belongs to the teams from the top 5 leagues. The top 5 leagues dominate European football both financially and competitively. The inequality is not present just among the teams from the top 5 leagues and others but also present among the teams of top 5 associations as the empirical evidence suggests.

Over the past two decades, some leagues grew richer than the others, and the distribution of income has deteriorated. The direction of the increasing inequality and the decreasing competitive balance coincide with each other in favor of English and German clubs. This section discusses the distortion in the competitive balance and its correlation with the change in revenue sharing.

As Table 4 presents, points collected by French, Italian and Spanish teams do not differ significantly from the first period to the second in the Champions' League. Even though their performance did not change in terms of points collected, it has changed in other measures. Regarding win rates, French teams have performed considerably worse. In the first period, French teams managed to collect the same amount of points in both periods; however, in the first period, they have done it with 23 and in the latter with 30, which reflected on their win rate, which has decreased almost $10 \%$ percent. Both English and German clubs have managed to increase their win rates by about $10 \%$, as displayed in Table 5 . They performed better not only in winning percentages but also in collecting points. The only two leagues which managed to increase their revenue shares over the past two decades are the only two leagues that have managed to perform better in both performance measures. In the Champions' League, as the evidence suggests, some leagues are improving their performances, whereas some are performing worse. The change in the competition is aligned with the change in revenue distribution, which indicates that revenue generation and performance are correlated with each other.

When Number of Championships per Team and Top 16 Rankings measures are taken into consideration, it can be seen that in the first period English, Italian, and Spanish teams performed similarly in terms of acquiring the Last 16 and Quarter Final slots in the Champions' League. Spanish teams performed better in Quarter Finals and managed to acquire more Semi-Final slots. German teams are behind these three and the French teams follow them. Even though German teams' overall performance is relatively low, they have managed to qualify for the final four times and win the trophy twice in 10 seasons. Almost every two years a German team managed to proceed to the final. In the second period, French teams fell even further behind and could not even manage to qualify for a final. English and German teams have significantly performed better in terms of qualifying for the later rounds; however, 
they have failed to convert it to more trophies. Italian teams significantly performed worse in terms of quarter and semi-finals; however, they have managed to qualify for the final every time they've managed to qualify for a semi-final, and they've won 2 titles. A conversion rate of $66 \%$ ( 2 titles out of 3 finals) in the second period, compared to a conversion rate of $20 \%$ ( 1 title out of 5 final), in the first, is a remarkable improvement. Even though the conversion rate for the finals has improved, it should be noted that their conversion rate for the last 16 has dropped from $83.3 \%$ to $30.4 \%$. This drastic decrease indicates a deterioration in the overall performance of Italian teams. Spanish teams have managed to proceed more into the latter rounds of the tournaments and win more titles; however, their conversion rate has decreased. The conversion rates for the last 16 are $77.3 \%$ and $64.5 \%$ respectively for periods 1 and 2, whereas the rates for semi-finals are 50\% and $46.6 \%$. Twice, the final was played between two Spanish teams which means that at least one Spanish team was in the last five times, and they have managed to win all of them, which is an extraordinary performance, a $100 \%$ conversion rate for the finals. Even though the English teams have also managed to have at least one team in the final five times, they were only able to win twice meaning that they have a conversion rate of $40 \%$ for the finals.

Unlike Champions' League, the coefficient of variation of Associations' Club Coefficient points collected in the UEFA Cup and Europa League did not increase over the past two decades. The competition did not get more uneven among the teams from the top 5 leagues in terms of points collected; however, even though the level of competition did not deteriorate, there has been another change that can be deducted from Table 8. French and English teams performed significantly worse, whereas German and Spanish teams performed substantially better which indicates that the structure of competition changed even though the level did not. That is why Figure 4 is not as informative as Figure 3; such a structural change cannot be observed from the change in the CVs in the past two decades.

The initial hypothesis was that the clubs from the leagues which increase their revenue share should increase perform better; however, there is evidence to support the hypothesis in the investigated period for the English clubs in UEFA Cup (Europa League). An explanation, for the decrease in English teams' performances, can be provided with the help of the "Average League Positions." Previous season's domestic league position can be used as a proxy for relative team strength. The average league position of the teams competing in the UEFA Cup and Europa League from each league represents the average team strength. The correlation between the previous season's domestic league position and the performance in international competitions is expected to be negative. The average league position for the English teams has increased from 6.55 to 7.12 from Period 1 to Period 2 meaning that relatively worse teams are representing England in the second period. French, German and Italian leagues have improved their average league positions significantly (From 6.9 to $5.9,6.5$ to 5.4 and 6.2 to 5.6 respectively). German and Italian teams have performed better in the second period than the first however, the 
French teams performed worse which was expected due to the decrease in their revenue share. The Pearson Correlation Coefficient between the CV of average league position and the CV of Associations' Club Coefficient points is -0.5 for the 20 years, indicating a significant negative relationship between the two as expected. The average league position provides an explanation for the decrease in English teams' performance in UEFA Cup and Europa League.

Table 9 provides the Number of Championships per Team and Top 16 Rankings data for the UEFA Cup and Europa League. It can be seen that the Spanish teams have dominated the UEFA Europa League. Out of the possible ten titles, they have managed to win six of them (five of them won by Sevilla FC) in the second period. In the first period, both final slots and trophies were evenly distributed between the teams of the top 5 leagues; however, the only league other than Spain to win a UEFA Europa League title was England. Spanish teams did not only dominate in the number of titles but also dominated in the number of semi-finals and final slots. Their conversion rate for the last 16 is $76 \%$; out of 21 times they have managed to qualify for the last 16, and 16 times they have reached the quarter-finals. Out of the 20 English teams in the last 16 only eight of them managed to qualify for the quarterfinals which are a conversion rate of $40 \%$. As winning percentages and points collected suggested, the only other league which performed better than the first period is the German league in UEFA Cup and Europa League. The findings summarized in Table 9 are aligned with the previous findings.

When Figure 5 is examined, the correlation between the CV of Points and CV of revenue is easy to observe. The CV curves move in the same direction over the last two decades. As the variation in revenue of the leagues increases, so does the inequality in competition and vice versa. The Pearson Correlation Coefficient between the CV of revenue and the CV of points has been 0.72 indicating a high degree of correlation, which is illustrated in the figure as well.

The distortion in revenue sharing among the top 5 leagues, presented by Figures 1 , 2 and 5 , is influential on performance. The leagues who have managed to increase their share in the total revenue from 1996/1997 to 2015/2016 have performed better in the later seasons of the period. Also, the overall level of competition has decreased as the distribution of revenue deteriorated. The competitive imbalance between the top 5 leagues is increasing due to the change in revenue sharing. Even though the European football market is growing rapidly as a whole, in the past two decades, English and German teams have grown relatively richer. As English and German clubs increased their revenues, they have also increased their competitive power.

Richest 20 clubs of Europe generated about 7.41 billion euros revenue in total in the $2015 / 2016$ season which is more than $30 \%$ of the total revenue generated by the top 5 leagues (Deloitte, 2017). Out of the top 20 teams, eight of them and out of the top 10 five of them are English teams. Financially English teams are dominating European football, and only a few other teams can compete with the English teams both on 
and off the pitch. Only one club, FC Porto, which was not in the top 10, has managed to win the Champions' League in the last 20 seasons. Out of possible 40 final slots, only five of them were taken by teams which are not among the richest 20 and the last was in the 2003/2004 season. The richest top 10 teams have been the same in the past four seasons. The difference between the 10th richest and the 11th richest teams was seven million euros in the 2012/2103 season, whereas it is 50 million euros in the 2016/2017 season (Deloitte, 2014, 2018). The gap between the richest ten and the others is widening, and it is influential on competitive balance.

One might argue that the rich teams are rich because they are successful, but that's not the case. Even though the prize money has been increased considerably over the past years, especially for the Champions' League, the share of prize money in the total revenue is about $10 \%$ for the top 10 teams (UEFA, 2018 \& Deloitte 2018). In a few hundreds of millions of revenue, few tens of millions are not decisive. The average share of prize money for the top 20 clubs, between 2006/2007 and $2010 / 2011$ seasons, was $11.9 \%$, whereas it was $10.4 \%$ between $2011 / 2012$ and 2016/2017 seasons (UEFA, 2018 \& Deloitte 2018). The share of prize money collected from UEFA competitions is decreasing; hence, the reliance of teams on it.

Manchester United was the highest revenue-generating team in the 2015/2016 season, and they did not even compete in the Champions' League. The importance of UEFA competitions' revenue is decreasing every day, and teams make it to the top 10 richest teams list even without collecting any prize money. Between the seasons 2006/2007 and 2010/2011, three teams made it to the top 10 richest list without competing in the Champions' League; however, they participated in the UEFA Europa League. Their shares of prize money in total revenue were 1.5\% (Bayern Munich in 2007/2008 season), 2\% (AC Milan in 2008/2009 season), and 3\% (Liverpool in $2010 / 2011$ season). In the five seasons between $2011 / 2012$ and $2016 / 2017$, eight teams were making it to the top 10 richest list without participating in the Champions' League, and seven of them did not even participate in the UEFA Europa League hence did not collect any prize money at all.

The importance of prize money is decreasing for the richest teams which are also the teams who have been winning the Champions' League in the past decade. The 19th most revenue-generating club of Europe in the 2016/2017 season was Internazionale, which generated 179.2 million Euros and only $4 \%$ of it was prize money collected from UEFA Europa League. Clubs do not depend on prize money anymore; even the Champions' League revenue is losing its importance for the richest clubs. When compared to the Champions' League, UEFA Europa League revenues are almost negligible. The huge gap between the competitions, in terms of revenue, is adversely affecting the effort and importance placed on Europa League games. Perhaps this is the main reason why English teams performed worse in UEFA Europa League games in the second period.

There are 98 teams in total, competing every season, in the top 5 leagues. Only several of them have a chance to win the biggest honor in European football, the 
Champions' League. The competitive imbalance is present not only between clubs from the top 5 leagues and the others but also between the clubs of the top 5 leagues. The Asian funds flowing to European football are building new superpowers such as Paris Saint-Germain and Manchester City which are the newest members of the richest 10 list. Paris Saint-Germain, the 6th richest club of Europe in the 2015/2016 season, generated $35 \%$ of the total revenue generated by the French teams, whereas the 5 th richest Manchester City could only generate $\% 3$ of the total revenue generated by the English teams. 35\% of the French league's revenue is less than $3 \%$ of the English league revenue; that's how unequal European football has become over the last decades (Deloitte, 2017). European football is losing its competitive balance and money has become a success in European football.

Lesser teams of Europe have a very slim chance of succeeding anything significant in Champions' League. Other than few teams, no others can match the English teams and the two giants of Spain, Real Madrid and FC Barcelona, which produce about $60 \%$ of the total revenue generated by the Spanish teams. The increasing trend German teams have in revenue distribution might bring them more trophies in the following seasons. As revenue is getting more and more unequally distributed, the domination of the few grows over the masses. It would be more realistic to target UEFA (Europa League) Cup for the other teams. If required financial adjustments were to be made UEFA Cup prize money could enable the transition from being a "UEFA Cup team" to a "Champions' League team". Sadly, even Sevilla FC (who had won the UEFA Europa League five times between 2005/2006 - 2015/2016) could not complete this transition and outperform itself, in the Champions' League or Spanish La Liga, during their reign in the UEFA Europa League. There is a rigid financial barrier between the richest 5-10 teams and the others; unfortunately, the governing bodies are not interested in demolishing these barriers. The only way a club can overcome the financial barrier is with the help of foreign funds such as the case of Manchester City and Paris Saint-Germain. Even the underdog champion of the Premier League in $2015 / 2016$, Leicester City, is owned by a foreign investor. The analysis conducted here investigated the period between 1996/1997 and 2015/2016 seasons. The evidence suggests that Premier League teams will be winning more trophies in the following seasons in accordance with their growing revenues. It should be noted Premier League teams have managed to qualify for the final three times in both the UEFA Europa League and Champions' League in the following three seasons of the investigation period; hence, the expectations were met. The growing revenues of Premier League teams are enabling them to dominate international tournaments.

Revenue sharing is a critical issue in European football, and there is evidence that inequality is growing. It can be concluded that changes in revenue generation and competitive balance are correlated with one another. Attention has to be paid in revenue sharing due to its adverse effects on competition, which will eventually affect the demand for football. Even the super-heroes will not exist if there are no super-villains. The giant clubs need competition and strong opponents. If European football lacks competition, even the biggest clubs in Europe might lose their financial 
power. What needs to be changed in European football is the distribution of income so that fans witness more fairy tales such as FC Porto's in 2004 or Leicester City's in 2016.

\section{Limitations and Suggestions for Future Studies}

There were some limitations to this study like there are in all studies. The main limitations this study faced were methodological limitations, which prevented the extension of the analysis to the whole of European football. Due to the lack of data regarding the other leagues of Europe, the investigation on revenue distribution was limited with the top 5 leagues and was limited with a period of 20 seasons.

The two main sources of data for this study, Deloitte's Annual Review of Football and Money League, have released their 26th and 21st editions, respectively. The financial data regarding the top 5 leagues as a whole cannot be found from any other sources hence, the period which was investigated could not be extended. The Annual Review of Football has started releasing the data for the total revenue generated by European football with the 2006/2007 season. The availability of data for ten seasons regarding the total revenue generated by the European football prevented the investigation of the trend in the top 5 leagues' share in the whole European football and its influence on competitive balance. If there was sufficient data, the performance of the top 5 league's teams' against the teams from other leagues could have been investigated and any present trends could have been identified. The revenues generated by the other major leagues such as Portugal, Ukraine, Russia, Netherlands, Turkey, Greece, and Belgium were also not available for every season, therefore, the analysis which was done for the top 5 leagues could not be done for the other leagues.

As more annual reports regarding football finance in Europe are published this study could be updated to see if the trend in the competitive balance is continuous. Furthermore, if data regarding the other major leagues of Europe can be collected, an extension could be made, and the competitive balance in European football could be investigated in a broader sense. Even though financial regulations have been stricter in recent years by the regulatory bodies of European football, foreign investors are injecting funds into clubs in the name of "soft loans." The injection of funds distorts the revenue generation mechanism, which enables clubs to spend more than their revenues. The high interest shown by the billionaires from all around the world in European football is shifting the balance of power which makes it another subject that requires further attention.

\section{References}

BBC. (2006, July 26). Punishments cut for Italian clubs. Retrieved on September 10, 2017, from http://news.bbc.co.uk/sport1/hi/football/europe/5215178.stm

BBC. (2015, February 10). Premier League in record f5.14bn TV rights deal. Retrieved on September 3, 2017, from http://www.bbc.com/news/business-31379128 
Behname, M. (2012). The Compare of Concentration and Efficiency in Banking Industry: Evidence from the OPEC Countries. Eurasian Journal of Business and Economics, 15-24.

Buzzacchi, L., Szymanski, S., \& Valletti, T. (2003). Equality of Opportunity and Equality of Outcome: Open Leagues, Closed Leagues and Competitive Balance. Journal of Industry, Competition and Trade, 3(3), 167-186. https://doi.org/10.1023/A:1027464421241

Deloitte. (2013, July). Annual Review of Football Finance 2013, Deloitte Sports Business Group. Retrieved on August 20, 2017, from https://www2.deloitte.com/content/dam/Deloitte/uk/Documents/sports-businessgroup/deloitte-uk-sbg-arff-2013-highlights-download.pdf

Deloitte. (2015, July). Annual Review of Football Finance 2015, Deloitte Sports Business Group. Retrieved on August 20, 2017, from https://www2.deloitte.com/us/en/pages/aboutdeloitte/articles/annual-review-of-football-finance.html

Deloitte. (2017, July). Annual Review of Football Finance 2017, Deloitte Sports Business Group. Retrieved on August 22, 2017, from https://www2.deloitte.com/content/dam/Deloitte/uk/Documents/sports-businessgroup/deloitte-uk-annual-review-of-football-finance-2017.pdf

Deloitte. (2018, January). Annual Review of Football Finance 2017, Deloitte Sports Business Group. Retrieved March 10, 2018, from https://www2.deloitte.com/uk/en/pages/sports-business-group/articles/deloitte-footballmoney-league.html

Depken, C. (1999). Free-Agency and the Competitiveness of Major League Baseball. Review of Industrial Organization, 14, 205-2017. https://doi.org/10.1023/A:100778830

Di Betta, P., \& Amenta, C. (2010). A Die-Hard Aristocracy: Competitive Balance in Italian Soccer, 1929-2009. Rivista Di Diritto Ed Economia Della Sport, 6(2), 13-39. Retrieved from https://papers.ssrn.com/sol3/papers.cfm?abstract_id=1975723

Dietl, H., Grossmann, M., \& Lang, M. (2011). Competitive Balance and Revenue Sharing in Sports Leagues with Utility-Maximizing Teams. Journal of Sports Economics, 12(3), 284-308. https://doi.org/10.1177/1527002511404787

Eurostat. (2017, 09 1). Eurostat - GDP and main components. Retrieved on 09/03/2017, from http://appsso.eurostat.ec.europa.eu/nui/show.do?dataset=namq_10_gdp\&lang=en

FIFA. (2017, September 7). FIFA/Coca-Cola World Ranking (Men's Ranking). Retrieved on September 14, 2017, from http://www.fifa.com/fifa-world-ranking/rankingtable/men/index.html

Forrest, D., \& Simmons, R. (2002, June 20). Outcome uncertainty and attendance demand in sport: the case of English soccer. Journal of the Royal Statistical Society, 51(2), 229-241. https://doi.org/10.1111/1467-9884.00314

Fort, R., \& Quirk, J. (1995). Cross-subsidization, Incentives, and Outcomes in Professional Team Sports Leagues. Journal of Economic Literature, 33(3), 1265-1299.

Garcia, J., \& Rodriguez, P. (2002, February 1). The Determinants of Football Match Attendance Revisited Empirical Evidence from the Spanish Football League. Journal of Sports Economics, 3(1), 18-38. https://doi.org/10.1177/152700250200300103

Goossens, K. (2006). Competitive Balance in European Football: Comparison by Adapting Measures: National Measure of Seasonal Imbalance and Top 3. Rivista Di Diritto Ed Economia Della Sport, 2(2), 77-122. 
An Empirical Study of Revenue Generation and Competitive Balance Relationship ...

Horowitz, I. (1997). The Increasing Competitive Balance in Major League Baseball. Review of Industrial Organization, 12(3), 373-387. https://doi.org/10.1023/A:1007799730191

Humphreys, B. (2002). Alternative Measures of Competitive Balance in Sports Leagues. Journal of Sports Economics, 3(2), 133-148. https://doi.org/10.1177/152700250200300203

Jann, B. (2016). Estimating Lorenz and concentration curves. The Stata Journal, 16(4), 837866. https://doi.org/10.1177/1536867X1601600403

Késenne, S. (2000, February). Revenue Sharing and Competitive Balance in Professional Team Sports. Journal of Sports Economics, 1(1), 56-65. https://doi.org/10.1177/152700250000100105

Lorenz, M. O. (1905, June). Methods of Measuring the Concentration of Wealth. Publications of the American Statistical Association, 9(70), 209-219. https://doi.org/10.2307/2276207

Michie, J., \& Oughton, C. (2004). Competitive Balance in Football: Trends and Effects. Birkbeck University of London. London: Football Governance Research Centre.

Miller, S. (2017, June 4). Champions League: Why English clubs have failed in Europe - and how they aim to change it. Retrieved September 11, 2017, from Daily Star - Sport: http://www.dailystar.co.uk/sport/football/619575/Champions-League-final-ManchesterUnited-Man-City-Chelsea-Liverpool-Tottenham-Europe

Oberstone, J. (2011). Comparing Team Performance of the English Premier League, Serie A, and La Liga for the 2008-2009 Season. Journal of Quantitative Analysis in Sports, 7(1). https://doi.org/10.2202/1559-0410.1280

Quirk, J., \& Fort, R. (1997). Pay Dirt: The Business of Professional Team Sports. New Jersey: Princeton University Press.

Sala-Garrido, R., Carrion, V. L., Esteve, A. M., \& Bosca, J. (2009). Analysis and Evolution of Efficiency in the Spanish Soccer League (2000/01 - 2007/08). Journal of Quantitative Analysis in Sports, 5(1). https://doi.org/10.2202/1559-0410.1143

Scully, G. (1974). Pay and Performance in Major League Baseball. The American Economic Review, 64(6), 915-930. Available at: https://www.jstor.org/stable/1815242

Sommers, P., \& Quinton, N. (1982). Pay and Performance in Major League Baseball: The Case of the First Family of Free Agents. The Journal of Human Resources, 17(3), 426-436. https://doi.org/10.2307/145589

Szymanski, S. (2001). Income Inequality, Competitive Balance and the Attractiveness of Team Sports: Some Evidence and a Natural Experiment from English Soccer. The Economic Journal, 111(469), 69-84. https://doi.org/10.1111/1468-0297.00599

Total Sportek. (2016, February 4). Spanish La Liga New 3 Year TV Deal Worth $€ 2.65$ billion (2016-19). Retrieved September 3, 2017, from http://www.totalsportek.com/money/spanishla-liga-new-3-year-tv-deal-worth-e2-65-billion/

Transfermarkt. (2016, May 30). Transfermarkt - Transfer \& Rumours. Retrieved on August 30, 2017, from https://www.transfermarkt.com/statistik/transfertage

UEFA. (2015, June 30). Financial fair play: all you need to know. Retrieved on August 22, 2017, from http://www.uefa.com/community/news/newsid=2064391.html

WorldFootball. (2012, August 10). Ukraine " Premyer Liga 2011/2012 " Attendance » Home matches. Retrieved September 12, 2017, from http://www.worldfootball.net/attendance/ukr-premyer-liga-2011-2012/1/ 
Selçuk ÖZAYDIN \& Murat DONDURAN

WorldFootball. (2017, May 30). WorldFootball- Europe Winners. Retrieved on August 25, 2017, from http://www.worldfootball.net/winner/europa-league/

WorldFootball. (2017, May 30). WorldFootball- Europe Winners. Retrieved on August 25, 2017, from http://www.worldfootball.net/winner/champions-league/

Zimbalist, A. (2002). Competitive Balance in Sports Leagues An Introduction. Journal of Sports Economics, 3(2), 111-121. https://doi.org/10.1177/152700250200300201 